\title{
Pengaruh Status Gizi Ibu Hamil dan Status Sosial Ekonomi Terhadap Panjang Badan Lahir Bayi dan Kejadian Stunting di Kabupaten Langkat Sumatera Utara
}

\author{
${ }^{1}$ Lusiatun, ${ }^{1}$ Kismiasih Adethia, ${ }^{1}$ Asnita Sinaga \\ Program Studi Kebidanan Program Sarjana Terapan, STIKes Mitra Husada Medan
}

Jln. Pintu Air IV Pasar 8 Kelurahan Kwala Bekala Kecamatan Medan Johor - Medan 20142

Email : lusiatun12@gmail.com

DOI: $\underline{10.33859 / \mathrm{dksm} . v 11 \mathrm{i} 1.580}$

\begin{abstract}
Abstrak
Latar Belakang: Indonesia saat ini masih menghadapi permasalahan gizi yang berdampak serius terhadap kualitas sumber daya manusia yaitu stunting. Stunting pada anak menunjukkan kondisi gagal tumbuh pada anak akibat kekurangan gizi kronis sejak bayi dalam kandungan hingga usia dua tahun. Tujuan: Tujuan penelitian ini adalah untuk mengetahui pengaruh status gizi ibu hamil, status sosial ekonomi terhadap panjang badan lahir dan kejadian stunting di Kabupaten Langkat Sumatera Utara tahun 2019.

Metode: Penelitian ini merupakan penelitian analitik observasional dengan pendekatan waktu retrospektif. Sampel dalam penelitian ini adalah anak balita usia 12-59 bulan di Wilayah Kerja Puskesmas Secanggang, Kabupaten Langkat pada tahun 2019. Jumlah sampel dalam penelitian ini adalah 30 anak yang mengalami stunting dan 30 yang tidak mengalami stunting. Teknik sampling yang digunakan adalah purposive sampling. Uji statistik Regresi Logistik Ganda.

Hasil: Ada pengaruh status gizi ibu hamil terhadap stunting $(\mathrm{OR}=0,23 ; 95 \% \mathrm{CI}=0,069-0,774$; $\mathrm{p}=0,018)$, sedangkan status sosial orang tua tidak signifikan terhadap stunting dengan $(\mathrm{OR}=0,86$; $95 \% \mathrm{CI}=0,378-1,989 ; \mathrm{p}=0,736)$. Pada status gizi ibu hamil terhadap panjang badan bayi $(\mathrm{OR}=1,149$; $95 \% \mathrm{CI}=0,282-4,673 ; \mathrm{p}=0,847)$ dan status sosial ekonomi terhadap panjang badan bayi dengan $(\mathrm{OR}=0,396,95 \% \mathrm{CI}=0,116-1,349 ; \mathrm{p}=0,138)$.
\end{abstract}

Kesimpulan: Ada pengaruh status gizi ibu hamil terhadap kejadian stunting, sehingga ibu hamil harus memperhatikan status gizinya selama hamil.

Kata kunci: stunting, panjang badan lahir, status gizi ibu hamil, status sosial ekonomi 


\begin{abstract}
Bakground: Indonesia is currently still facing nutritional problems that have a serious impact on the quality of human resources, namely stunting. Stunting in children shows the condition of failure to grow in children due to chronic malnutrition from the baby in the womb until the age of two years. Purpose: The purpose of this study was to determine the effect of nutritional status of pregnant women, socioeconomic status on birth length and the incidence of stunting in Langkat District, North Sumatra in 2019.
\end{abstract}

Method: This research was an observational analytic study with a retrospective. The sample in this study were children aged 12-59 months in the Secanggang Health Center, Langkat. The number of samples in this study were 30 children who stunting and 30 who did not stunting. The sampling technique used was purposive sampling. Statistical test for Multiple Logistic Regression.

Results: There was an effect of nutritional status of pregnant women on stunting $(O R=0.23 ; 95 \%$ $C I=0.069-0.774 ; p=0.018)$, while the social status of parents was not significant to stunting with $(O R=0.86 ; 95 \% C I=0.378-1.989 ; p=0.736)$. On the nutritional status of pregnant women for the length of the baby $(O R=1.149 ; 95 \% C I=0.282-4.673 ; p=0.847)$ and socioeconomic status for the length of the baby with $(O R=0.396,95 \% C I=0.116-1.349 ; p=0.138)$.

Conclusion: There is an influence of the status of nutritional pregnant women on the incidence of stunting, so pregnant women must pay attention to the nutritional status during pregnancy.

Keywords: stunting, body length of birth, nutritional status of pregnant women, socioeconomic status 
Dinamika Kesehatan Jurnal Kebidanan dan Keperawatan Vol 11 No. 1 Juli 2020 ( ISSN: 2086-3454 EISSN: 2549-4058)

url: http://ojs.dinamikakesehatan.unism.ac.id DOI : https://doi.org/10.33859/dksm.v11i1

Pengaruh Status Gizi Ibu Hamil dan Status Sosial Ekonomi Terhadap Panjang Badan Lahir Bayi dan Kejadian Stunting di Kabupaten Langkat Sumatera Utara

\section{Pendahuluan}

Indonesia saat ini masih menghadapi permasalahan gizi yang berdampak serius terhadap kualitas Sumber Daya Manusia (SDM). Salah satu permasalahan tersebut adalah masih tingginya anak balita pendek (stunting)(TIM Nasional Percepatan Penanggulangan Kemiskinan, 2017). Stunting merupakan gangguan pertumbuhan dan perkembangan yang dialami anak-anak dari gizi buruk, infeksi berulang, dan stimulasi psikososial yang tidak memadai. Anak dikatakan stunting jika tinggi badan mereka untuk seusianya lebih dari dua standar deviasi di bawah standar median(World Health Organization, 2018). Kerdil (stunting) pada anak menunjukkan kondisi gagal tumbuh pada anak akibat kekurangan gizi kronis sejak bayi dalam kandungan hingga usia dua tahun. Sehingga periode 1000 hari pertama kehidupan (HPK) harus mendapat perhatian khusus karena mempengaruhi tingkat pertumbuhan fisik, kecerdasan, dan produktivitas anak di masa depan(TIM Nasional Percepatan Penanggulangan Kemiskinan, 2017).

Stunting termasuk dalam empat program prioritas pembangunan kesehatan di Indonesia pada tahun 2015-2019. Empat program prioritas tersebut adalah penurunan angka kematian ibu dan bayi, penurunan prevalensi balita pendek (stunting), pengendalian penyakit menular dan pengendalian penyakit tidak menular. Upaya penurunan prevalensi balita pendek melalui peningkatan status gizi masyarakat yang tercantum dalam sasaran pokok Rencana Pembangunan jangka Menengah Tahun 2015-2019. Target penurunan prevalensi stunting (pendek dan sangat pendek) pada anak baduta (dibawah 2 tahun) adalah menjadi 28\% (RPJMN, 2015 - 2019) (Kementerian Perencanaan Pembangunan Nasional/ Badan Perencanaan Pembangunan Nasional, 2014).

Menurut WHO stunting menjadi masalah kesehatan masyarakat bila prevalensi stunting $\geq 20 \%$. Global Nutrition Report tahun 2014 menunjukkan Indonesia termasuk dalam 17 negara, di antara 117 negara, yang mempunyai tiga masalah gizi yaitu stunting, wasting dan overweight pada balita (Kemenkes RI, 2017). Hasil Riset Kesehatan Dasar Tahun 2013 prevalensi stunting di Indonesia mencapai 37,2\% (Sandjojo, 2018). Sedangkan pada tahun 2015 melalui Pemantauan Status Gizi (PSG) prevalensi stunting di Indonesia sebesar 29\%. Di wilayah Sumatera Utara berdasarkan data PSG tahun 2015 prevalensi stunting mencapai 33,2\% dengan perbandingan 15,4 sangat pendek dan 17,8 pendek (Kemenkes RI, 2017). Pada tahun 2013 terdapat 4 kabupaten tertinggi angka prevalensi stunting yakni Kabupaten Langkat (55,48\%), Kabupaten Padang Lawas (54,86\%), Nias Utara (54,83\%), Gunung Sitoli (52,32\%). Langkat merupakan salah satu kabupaten dengan jumlah stunting tertinggi yakni sebesar 55,48\% (TIM Nasional Percepatan Penanggulangan Kemiskinan, 2017).

\section{Metode Penelitian}


Penelitian ini merupakan penelitian analitik observasional dengan desain studi retrospektif. Penelitian ini dilakukan di Wilayah Kerja Puskesmas Secanggang Kabupaten Langkat Sumatera Utara. Pengukuran stunting dengan cara mengukur tinggi badan anak dengan menggunakan mikrotoise. Untuk mengetahui status gizi ketika ibu hamil, status sosial ekonomi dan panjang badan ketika lahir menggunakan rekam medik yang ada di Puskesmas. Teknik sampling yang digunakan adalah purposive sampling. Sampel dalam penelitian ini adalah anak balita usia 12-59 bulan sebanyak 60 anak dengan 30 anak mengalami stunting dan 30 tidak mengalami stunting. uji statistik dalam penelitian ini menggunakan Regresi Logistik Ganda.

\section{Hasil}

Tabel 1.Pengaruh status gizi ibu hamil dan status sosial ekonomi terhadap panjang badan bayi

\begin{tabular}{|l|l|l|l|l|}
\hline Variabel & $\mathrm{p}$ & $\operatorname{Exp}(\mathrm{B})$ & \multicolumn{2}{|l|}{$95 \%$ C.I.for EXP(B) } \\
\cline { 3 - 5 } & & & Lower & Upper \\
\hline $\begin{array}{l}\text { Status Gizi } \\
\text { Ibu Hamil }\end{array}$ & .847 & 1.149 & .282 & 4.673 \\
\hline $\begin{array}{l}\text { Status Sosial } \\
\text { Ekonomi }\end{array}$ & .138 & .396 & .116 & 1.349 \\
\hline
\end{tabular}

Berdasarkan tabel 1 baik pada status gizi ibu hamil dan status sosial ekonomi tidak memiliki pengaruh yang signifikan terhadap panjang badan lahir bayi, masing-masing sebesar $(\mathrm{OR}=1,149 ; 95 \% \mathrm{CI}=0,282-4,673$; $\mathrm{p}=0,847)$ dan $(\mathrm{OR}=0,396,95 \% \mathrm{CI}=0,116-1,349 ; \mathrm{p}=0,138)$. Faktor panjang badan lahir bayi dapat dipengaruhi oleh faktor lainnya.

Tabel 2. Pengaruh status gizi ibu hamil dan status sosial ekonomi terhadap kejadian stunting

\begin{tabular}{|l|l|l|l|l|}
\hline \multirow{2}{*}{ Variabel } & $\mathrm{p}$ & $\operatorname{Exp}(\mathrm{B})$ & \multicolumn{2}{|l|}{$\begin{array}{l}\text { 95\% } \\
\text { EXP(B) }\end{array}$} \\
\cline { 4 - 5 } & & Cower & Upper \\
\hline $\begin{array}{l}\text { Status Gizi } \\
\text { Ibu Hamil }\end{array}$ & .018 & .231 & .069 & .774 \\
\hline $\begin{array}{l}\text { Status Sosial } \\
\text { Ekonomi }\end{array}$ & .736 & .867 & .378 & 1.989 \\
\hline
\end{tabular}

Berdasarkan tabel 2, status gizi ibu hamil memiliki pengaruh yang signifikan terhadap kejadian stunting $(\mathrm{OR}=0,23 ; 95 \% \mathrm{CI}=0,069-0,774 ; \mathrm{p}=0,018)$. Semakin baik status gizi maka risiko untuk mengalami sunting semakin kecil, begitu pula sebaliknya. Sedangkan status sosial ekonomi orang tua tidak ada pengaruh yang signifikan terhadap stunting dengan $(\mathrm{OR}=0,86 ;, 95 \% \mathrm{CI}=0,378-1,989 ; \mathrm{p}=0,736)$.

\section{Pembahasan}

Berdasarkan hasil penelitian pada tabel 2, terdapat pengaruh status gizi ibu hamil terhadap kejadian stunting. Penelitian ini didukung oleh penelitian yang dilakukan Fajrina tahun 2016 dengan hasil adanya hubungan status gizi ibu hamil dengan kejadian stunting, dimana ibu yang memiliki status gizi buruk beresiko 4,154 kali melahirkan anak stunting. Status gizi ibu selama kehamilan dapat dimanifestasikan sebagai keadaan tubuh akibat dari pemakaian, penyerapan dan penggunaan makanan yang dapat mempengaruhi pertumbuhan dan 
Dinamika Kesehatan Jurnal Kebidanan dan Keperawatan Vol 11 No. 1 Juli 2020 ( ISSN: 2086-3454 EISSN: 2549-4058)

url: http://ojs.dinamikakesehatan.unism.ac.id DOI : https://doi.org/10.33859/dksm.v11i1

Pengaruh Status Gizi Ibu Hamil dan Status Sosial Ekonomi Terhadap Panjang Badan Lahir Bayi dan Kejadian Stunting di Kabupaten Langkat Sumatera Utara

perkembangan janin. Gizi ibu waktu hamil sangat penting untuk pertumbuhan janin yang dikandungnya (Fajrina \& Syaifudin, 2016).

Penelitian yang dilakukan oleh Puparini dkk, tahun 2017 didapatkan bahwa faktor risiko panjang bayi lahir rendah menunjukkan bahwa 41.3\% ditentukan oleh status gizi ibu hamil dengan faktor risiko utama adalah defisiensi vitamin A (Pusparini, 2017). Hasil penelitian ini tidak sejalan dengan hasil penelitian pada tabel 1 bahwa status gizi ibu hamil tidak mempengaruhi panjang badan bayi pada saat lahir. Dalam hal peneliti tidak secara khusus menilai gizi yang kurang pada ibu hamil secara spesifik, hanya menilai dari pertambahan berat badan selama kehamilan.

Sejalan dengan penelitain Irviana dan Faramita bahwa tidak ada hubungan antara pendapatan orang tua terhadap kejadian stunting pada anak usia 24-59 bulan di wilayah kerja Puskesmas Barombong. Pendapatan yang tinggi tidak selamanya meningkatkan konsumsi zat gizi yang dibutuhkan oleh tubuh, tetapi kenaikan pendapatan akan menambah kesempatan untuk memilih bahan makanan dan meningkatkan konsumsi makanan yang disukai meskipun tidak bergizi tinggi. Pendapatan yang rendah, biasanya mengkonsumsi makanan yang lebih murah dan menu yang kurang bervariasi, sebaliknya pendapatan yang tinggi umumnya mengkonsumsi makanan yang lebih tinggi harganya, tetapi penghasilan yang tinggi tidak menjamin tercapainya gizi yang baik (Irviana \& Faramita, 2014) .

Menurut hasil penelitian Simbolon, dkk yang dilakukan pada tahun 2015 didapatkan hasil sosial ekonomi tidak berhubungan signifikan dengan prevalensi panjang badan lahir pendek pada bayi baru lahir (Simbolon et al., 2015). Hasil penelitian ini tersebut sejalan dengan hasil penelitian pada tabel 1. Banyak faktor lain yang mempengaruhi panjang badan lahir bayi. Dalam hal ini belum dilakukan penelitian secara mendalam oleh peneliti.

\section{Kesimpulan dan Saran}

Ada pengaruh status gizi ibu hamil terhadap kejadian stunting. Tidak terdapat pengaruh antara status gizi ibu hamil terhadap panjang badan bayi baru lahir, serta tidak ada pengaruh status ekonomi terhadap kejadian stunting dan panjang badan bayi baru lahir.

Diharapkan kepada ibu hamil agar selama kehamilan mengkonsumsi makanan yang bergizi dan memperhatikan kenaikan berat badannya dan bagi peneliti selanjutnya hendaknya memberikan intervensi kepada ibu hamil agar bayi yang dilahirkan tidak mengalami stunting.

\section{Ucapan Terima kasih}

Terima kasih kepada STIKes Mitra Husada Medan yang telah memberikan kesempatan kepada kami untuk melakukan penelitian ini dan semua pihak yang telah membantu proses penelitian ini.

\section{Daftar Pustaka}


Fajrina, N., \& Syaifudin. (2016). Hubungan Faktor Ibu Dengan Kejadian Stunting Pada Balita Di Puskesmas Piyungan Kabupaten Bantul. Fakultas Ilmu Kesehatan Universitas 'Aisyiyah Yogyakarta.

Irviana, I., \& Faramita, R. (2014). Hubungan Faktor Sosial Ekonomi Keluarga dengan Kejadian Stunting Anak Usia 24-59 Bulan di Wilayah Kerja Puskesmas Barombong Kota Makassar Tahun 2014. Al-Sihah : Public Health Science Journal, 6(2), 63-75. https://doi.org/10.1121/1.394925

Kemenkes RI. (2017). Infodatin Pusat Data dan Informasi Kementerian Kesehatan RI: Situasi Balita Pendek.

Kementerian Perencanaan Pembangunan Nasional/ Badan Perencanaan Pembangunan Nasional. (2014). Rencana Pembangunan Jangka Menengah Nasional (RPJMN) 2015-2019. https://doi.org/10.1088/1757$\underline{899 X / 114 / 1 / 012081}$

Pusparini. (2017). Status Gizi Ibu Sebagai Faktor Risiko Panjang Bayi Lahir Rendah Serta Dampaknya Terhadap Pertumbuhan Linier dan Perkembangan Kognitif Anak Usia Tiga Tahun. Institut Pertanian Bogor.

Sandjojo, E. putro. (2018). Buku saku desa dalam penanganan stunting. Buku Saku Desa Dalam Penanganan Stunting.

Simbolon, D., Astuti, W. D., \& Andriani, L. (2015). Mekanisme Hubungan Sosial Ekonomi, Pemanfaatan Pelayanan Kesehatan, dan Kehamilan Risiko Tinggi ter- hadap Prevalensi Panjang Badan Lahir Pendek. Jurnal Kesehatan Masyarakat Nasional, 235 9(3), https://doi.org/http://dx.doi.org/10.21109/kesmas.v9i3.570.g454

TIM Nasional Percepatan Penanggulangan Kemiskinan. (2017). 100 Kabupaten/Kota Prioritas untuk Intervensi Anak Kerdil (Stunting).

World Health Organization. (2018). Stunting in A Nutshell. 